\title{
Combination of nanoparticle-based therapeutic vaccination and transient ablation of regulatory $T$ cells enhances anti-viral immunity during chronic retroviral infection
}

\author{
Torben Knuschke1, Olga Rotan², Wibke Bayer ${ }^{3}$, Viktoriya Sokolova², Wiebke Hansen ${ }^{1}$, Tim Sparwasser ${ }^{4}$,
} Ulf Dittmer ${ }^{3}$, Matthias Epple 2 , Jan Buer ${ }^{1}$ and Astrid M. Westendorf ${ }^{*}$

\begin{abstract}
Background: Regulatory T cells (Tregs) have been shown to limit anti-viral immunity during chronic retroviral infection and to restrict vaccine-induced T cell responses. The objective of the study was to assess whether a combinational therapy of nanoparticle-based therapeutic vaccination and concomitant transient ablation of Tregs augments anti-viral immunity and improves virus control in chronically retrovirus-infected mice. Therefore, chronically Friend retrovirus (FV)-infected mice were immunized with calcium phosphate (CaP) nanoparticles functionalized with TLR9 ligand $\mathrm{CpG}$ and $\mathrm{CD}^{+}$or $\mathrm{CD}^{+} \mathrm{T}$ cell epitope peptides (GagL $\mathrm{B5}_{-93}$ or Env gp70 ${ }_{123-141}$ ) of FV. In addition, Tregs were ablated during the immunization process. Reactivation of $\mathrm{CD}^{+}$and $\mathrm{CD}^{+}$effector T cells was analysed and the viral loads were determined.

Results: Therapeutic vaccination of chronically FV-infected mice with functionalized CaP nanoparticles transiently reactivated cytotoxic $C D 8^{+} T$ cells and significantly reduced the viral loads. Transient ablation of Tregs during nanoparticle-based therapeutic vaccination strongly enhanced anti-viral immunity and further decreased viral burden.

Conclusion: Our data illustrate a crucial role for $\mathrm{CD}^{+}{ }^{+}$Foxp3 $^{+}$Tregs in the suppression of anti-viral T cell responses during therapeutic vaccination against chronic retroviral infection. Thus, the combination of transient Treg ablation and therapeutic nanoparticle-based vaccination confers robust and sustained anti-viral immunity.
\end{abstract}

Keywords: Chronic retrovirus infection, Nanoparticles-based vaccine, Regulatory T cells

\section{Background}

Effector $\mathrm{T}$ cells are crucial for the elimination of intracellular pathogens. Especially cytotoxic $\mathrm{CD}^{+} \mathrm{T}$ cells are predominantly important for the control of virus infections, i.e. human immunodeficiency virus (HIV) [1] or hepatitis $\mathrm{C}$ virus (HCV) $[2,3]$. However, several evasion mechanisms of viruses, like viral evolution or exhaustion of effector $\mathrm{T}$ cells can contribute to persistent infection. Important inducer of dysfunctional CD8 ${ }^{+}$

\footnotetext{
*Correspondence: astrid.westendorf@uk-essen.de

${ }^{1}$ Institute of Medical Microbiology, University Hospital Essen, University of Duisburg-Essen, 45122 Essen, Germany

Full list of author information is available at the end of the article
}

$\mathrm{T}$ cells are virus-induced or virus-expanded regulatory $\mathrm{T}$ cells (Tregs). Tregs belong to a specialized $\mathrm{T}$ cell subset which is characterized by the expression of the transcription factor Foxp3 and unique suppressive capacities that can limit anti-viral immune responses [4-6]. It was demonstrated that the low responsiveness and reduced proliferation of virus-specific $\mathrm{T}$ cells during chronic viral infection is associated with the expansion of Tregs which also affects the cytotoxic activity of virus-specific $\mathrm{CD}^{+} \mathrm{T}$ cells $[6,7]$. Immune-based therapies have been considered as potent approach to efficiently reactivate impaired anti-viral effector immunity to control chronic viral infection. In this concern, depletion of Tregs during acute and chronic murine retroviral infection was 
shown to restore the functions of $\mathrm{CD}^{+} \mathrm{T}$ cells and to decrease viral loads $[5,6,8,9]$. The results suggest that Treg-mediated immunosuppression is a significant factor in the maintenance of chronic viral infections, and that Treg-targeted immunotherapy could be a valuable component in therapeutic strategies to treat chronic retroviral infections.

Additionally, promising trials to efficiently reactivate $\mathrm{CD}^{+} \mathrm{T}$ cell responses have been made by confronting patient-derived dendritic cells (DCs) with HIV-specific antigens to induce virus-specific immune responses $[10$, 11] or by directly targeting lymph nodes with peptidebased vaccine vehicles [12]. In this context, nanoparticulate structures are discussed to be ideal vaccine delivery vehicles [13]. Inorganic calcium phosphate $(\mathrm{CaP})$ nanoparticles are promising candidates for this purpose. Due to their small size $(\sim 100 \mathrm{~nm})$ and their non-toxicity CaP nanoparticles feature ideal properties as delivery vehicles across cell membranes [14, 15]. After functionalization with TLR ligands such as CpG or poly(I:C), CaP nanoparticles efficiently activate cells of the innate and adaptive immune system [14]. In a recent study, we have shown that prophylactic immunization of mice with $\mathrm{CaP}$ nanoparticles, functionalized with virus-derived $\mathrm{T}$ cell epitopes and the TLR9 ligand CpG, leads to an activation of DCs and in consequence induced strong antigen-specific $\mathrm{CD} 4^{+}$and $\mathrm{CD} 8^{+} \mathrm{T}$ cell response. Of note, this vaccination strategy resulted in a powerful protection against influenza virus and Friend retrovirus (FV) infection [16, 17]. In addition, therapeutic vaccination of chronically FV-infected mice efficiently reactivated effector $\mathrm{T}$ cells which led to a significant decrease in viral loads.

$\mathrm{FV}$ is an immunosuppressive retrovirus complex of the non-pathogenic Friend murine leukemia virus (F-MuLV) and the pathogenic, replication defective spleen focus forming virus (SFFV) [18]. Disease-resistant mouse strains can control acute infection, but develop a life-long chronic infection. This is associated with the expansion and activation of Tregs [19], which down-regulate virusspecific cytotoxic $\mathrm{CD} 8^{+} \mathrm{T}$ cell activity [6], a conspicuous feature which in fact was also seen in HIV infection [20]. As no appropriate mouse model for studying HIV infection exists, the well-described FV infection model has been accepted to be suitable to understand basic concepts in retroviral immunity and to test novel vaccination strategies [21-24].

In this study, we aimed to identify whether nanoparticle-based vaccination and concomitant modulation of inhibitory Treg responses in chronically retrovirus infected mice results in potent anti-viral immunity and improves viral control. To our knowledge, we show for the first time that the combinational immune-based therapy of $\mathrm{CaP}$ nanoparticle vaccination and Treg ablation efficiently reactivates the cytotoxic potential of $\mathrm{CD}^{+}$ effector $\mathrm{T}$ cells and leads to a dramatic drop in viral loads in chronic retroviral infection, stronger than each therapeutic treatment regimen alone. Thus, vaccine-induced reactivation of effector $\mathrm{T}$ cells during chronic viral infection is feasible but is strikingly enhanced by simultaneous immune modulation.

\section{Results}

Therapeutic vaccination of chronically infected mice with functionalized CaP nanoparticles transiently reactivates cytotoxic $\mathrm{CD}^{+} \mathrm{T}$ cells and reduce viral loads

Recently, we introduced functionalized $\mathrm{CaP}$ nanoparticles as excellent vaccination delivery system for the treatment of chronic retroviral infection [17]. Functionalized triple-shell $\mathrm{CaP}$ nanoparticles were prepared by subsequent precipitation and functionalization steps as described earlier $[14,16]$. In brief, $\mathrm{CaP}$ solid cores were loaded with $\mathrm{CpG}$ and $\mathrm{CD} 8^{+}$or $\mathrm{CD} 4^{+} \mathrm{T}$ cell epitope peptides $\left(\mathrm{GagL}_{85-93}\right.$ or Env gp70 $\left.{ }_{123-141}\right)$ of FV and finally coated with a second layer of $\mathrm{CaP}$ and an outer shell of CpG for colloidal stabilization (Additional file 1: Figure S1A). Vaccination of mice with functionalized CaP nanoparticles efficiently activates the major DC subsets, therefore mediating ideal requirements for the initiation of adaptive immune responses $[14,16]$. One shot-immunization of chronically FV infected mice with functionalized CaP nanoparticles reactivated virus-specific $\mathrm{T}$ cell responses accompanied by a significant decrease in viral loads with striking advantage over vaccination with soluble CpG ligand and viral peptides [17] (Additional file 1: Figure S1B-E).

\section{Foxp $3^{+} \mathrm{CD}^{+}$regulatory $\mathrm{T}$ cells down-regulate $\mathrm{T}$ cell responses after $\mathrm{CaP}$ nanoparticle vaccination}

We recently demonstrated that therapeutic vaccination with $\mathrm{CpG}$ and $\mathrm{FV}$-peptide functionalized $\mathrm{CaP}$ nanoparticles decreases the proportion of immunosuppressive $\mathrm{CD} 4^{+}$regulatory $\mathrm{T}$ cells 7 days after therapeutic vaccination [17]. Nonetheless, it was so far unclear if $\mathrm{CD} 4^{+}$ regulatory $\mathrm{T}$ cells counteract an efficient effector $\mathrm{T}$ cells response after therapeutic vaccination. To analyze this issue, FV-resistant C57BL/6 mice were infected with a high dose of FV to induce chronic infection. 6 weeks after infection, mice were therapeutically vaccinated subcutaneously with $\mathrm{CpG} / \mathrm{gp} 70 / \mathrm{GagL}$ functionalized $\mathrm{CaP}$ nanoparticles (Additional file 1: Figure S1B). Splenocytes were isolated from naïve, chronically infected (PBS), and therapeutically vaccinated mice (CaP nanoparticles) 7 and 14 days after treatment, and the percentage of $\mathrm{CD} 4^{+}$ regulatory $\mathrm{T}$ cells was determined. As expected, the proportion of $\mathrm{CD}^{+}$regulatory $\mathrm{T}$ cells was decreased 7 days after vaccination with $\mathrm{CaP}$ nanoparticles compared to 
PBS treated mice. However, we noticed that 14 days after vaccination this reduction was converted into an increase of $\mathrm{CD}^{+}$Foxp $^{+}$regulatory $\mathrm{T}$ cells compared to PBS treated chronically infected mice (Fig. 1a). To understand this effect we particularly analyzed the ratio between effector and regulatory $\mathrm{T}$ cells at these respective time points. Interestingly, we found that the ratio of fully activated $\mathrm{CD} 43^{+} \mathrm{CD} 4^{+}$and $\mathrm{CD} 43^{+} \mathrm{CD}^{+}$effector $\mathrm{T}$ cells over $\mathrm{CD} 4^{+}$Foxp $^{+}{ }^{+}$regulatory $\mathrm{T}$ cells was significantly elevated 7 days after $\mathrm{CaP}$ nanoparticle vaccination compared to PBS treatment; this effect was abolished 14 days after vaccination (Fig. 1b). To check whether the increased regulatory $\mathrm{T}$ cell frequency on day 14 after vaccination was the result of cell proliferation we stained for the proliferation marker Ki67. Of note, no significant differences were observed (Fig. 1c). As regulatory T cells are known to control virus-specific $\mathrm{CD}^{+} \mathrm{T}$ cell responses during chronic FV infection $[5,6,25]$, we analyzed the correlation between $\mathrm{CD}^{+}$effector $\mathrm{T}$ cells and regulatory $\mathrm{T}$ cells during vaccination. Importantly, we were able to identify a strong negative correlation between the percentage of FV-specific $\mathrm{CD}^{+} \mathrm{CD}^{+} 3^{+} \mathrm{GzmB}^{+} \mathrm{T}$ cells and percentage of $\mathrm{CD}^{+}{ }^{+} \mathrm{Foxp}^{+} \mathrm{T}$ cells in the spleen 14 days after vaccination with $\mathrm{CaP}$ nanoparticles. The higher the percentage of $\mathrm{CD}^{+}{ }^{+} \mathrm{Foxp}^{+}$regulatory $\mathrm{T}$ cells in the spleen the lower was the percentage of $\mathrm{GzmB}^{+} \mathrm{FV}$ specific $\mathrm{CD}^{+} \mathrm{T}$ cells (Fig. 1d). Interestingly, this kind of correlation was not seen in the PBS treated control mice (Fig. 1d) nor at day 7 after vaccination which could be due to the change in the $\mathrm{T}$ effector-Treg ratios (data not shown). These results clearly demonstrate that although $\mathrm{CD}^{+}{ }^{+}$and $\mathrm{CD}^{+}{ }^{+}$effector $\mathrm{T}$ cells expand after therapeutic one shot-vaccination with functionalized $\mathrm{CaP}$ nanoparticles, regulatory $\mathrm{T}$ cells still have a strong impact on virusspecific immunity.

\section{Transient ablation of regulatory $\mathrm{T}$ cells strongly enhances} the therapeutic effect of functionalized CaP nanoparticles Our results underline the powerful regulatory capacity of Foxp3 ${ }^{+} \mathrm{T}$ cells on $\mathrm{CD}^{+}$effector cells with cytotoxic potential during therapeutic vaccination of chronically FV-infected mice. To investigate whether ablation of regulatory $\mathrm{T}$ cells further improves the efficacy of functionalized $\mathrm{CaP}$ nanoparticles for therapeutic vaccination, we investigated chronically FV infected DEREG (DEpletion of REGulatory $\mathrm{T}$ cells) mice in which regulatory $\mathrm{T}$ cells can be selectively ablated by the injection of diphtheria toxin (DT) [26]. To ensure that the absence of Tregs will enhance cytotoxicity as well as $\mathrm{T}$ cell priming we decided to inject DEREG mice with DT 4 and 2 days before and 2 and 4 days after the vaccination with $\mathrm{CpG} /$ gp70/GagL-functionalized $\mathrm{CaP}$ nanoparticles at week 6 post FV infection (Fig. 2a), resulting in an up to $99 \%$ depletion of Foxp $3^{+}$regulatory T cells in naïve, PBS, and $\mathrm{CaP}$ nanoparticle treated mice until day 7 post vaccination (Fig. 2b). On day 7 after vaccination, splenocytes were isolated and analyzed for the expression of GzmB by $\mathrm{CD}^{+}$and $\mathrm{CD} 8^{+}$effector $\mathrm{T}$ cells. Interestingly, the strongest increase in the frequency of activated cytotoxic $\mathrm{CD}_{4}^{+} \mathrm{CD} 3^{+} \mathrm{GzmB}^{+}$and $\mathrm{CD}^{+}{ }^{+} \mathrm{CD} 43^{+} \mathrm{GzmB}^{+}$ $\mathrm{T}$ cells was observed after the combination of $\mathrm{CaP}$ nanoparticle vaccination and depletion of regulatory $\mathrm{T}$ cells. Although the depletion of Tregs led also to an increase in gag-specific cytotoxic $\mathrm{CD} 8^{+} \mathrm{T}$ cells, the combination of $\mathrm{CaP}$ nanoparticle vaccination and Treg ablation even stronger increased the amount of those cells compared to DT treatment alone or CaP nanoparticle vaccination alone (Fig. 2c). In addition, ex vivo restimulation of splenocytes with the GagL peptide revealed that the depletion of regulatory $\mathrm{T}$ cells during vaccination further augmented the number of IFN- $\gamma$ producing virus-specific $\mathrm{CD}^{+} \mathrm{T}$ cells compared to DT treatment or nanoparticle vaccination alone (Fig. 2d). The application of DT alone was not sufficient to significantly decrease the viral loads in mice. One shot-immunization with CpG/gp70/GagLfunctionalized $\mathrm{CaP}$ nanoparticles already reduced viral loads in the spleen, and this effect was further enhanced by depletion of regulatory $\mathrm{T}$ cells during the immunization process (Fig. 3). These data clearly demonstrate that affecting the number of regulatory $\mathrm{T}$ cells before therapeutic vaccination could be crucial to effectively treat chronic viral infection.

\section{Antagonizing chemokine receptor 4 on regulatory $T$ cells does not improve the anti-viral effect of therapeutic vaccination with functionalized $\mathrm{CaP}$ nanoparticles}

Depletion of regulatory T cells in humans, as performed in the transgenic DEREG mouse model, is still elusive. Regulatory $\mathrm{T}$ cell depletion by anti-CD25 monoclonal antibodies can lead to enhanced immunity; however, a CD25-targeted approach is associated with several drawbacks. First, regulatory $\mathrm{T}$ cell depletion might lead to appearance of autoimmune manifestations, as reported in experimental animals. Secondly, activated effector $\mathrm{CD}^{+}$and $\mathrm{CD}^{+}{ }^{+} \mathrm{T}$ cells also express $\mathrm{CD} 25$ and could also be eliminated by CD25 depletion [27]. Therefore, alternative approaches, focusing on inhibition instead of depletion of regulatory $\mathrm{T}$ cells might be of high interest for upcoming therapies.

Blockade of chemokine receptor 4 (CCR4) by an antagonist was recently reported to inhibit migration of regulatory $\mathrm{T}$ cells to tumors, and thereby enhancing anti-tumor vaccination [28, 29]. Human and murine regulatory $\mathrm{T}$ cells, but not naïve or effector $\mathrm{T}$ cells express CCR4, and the ligands for CCR4, CCL22 and CCL17, are mainly secreted by activated DCs and macrophages. So 

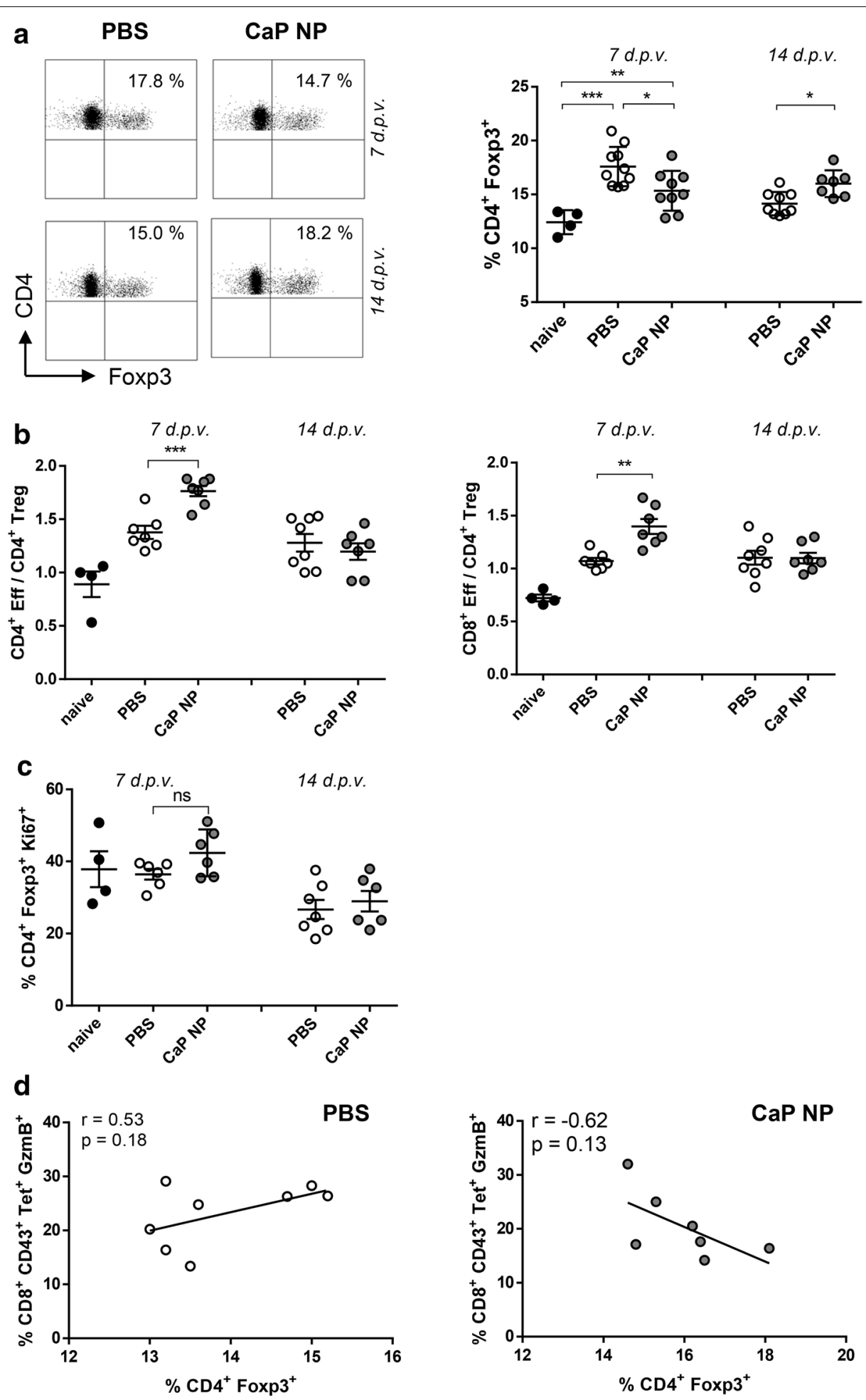

Fig. 1 Foxp $3^{+} \mathrm{CD} 4^{+}$regulatory T cells down-regulate T cell responses after CaP nanoparticle vaccination. a Frequencies of Foxp3 ${ }^{+} \mathrm{CD}^{+}{ }^{+}$regulatory T cells were determined by flow cytometry in naïve and chronically FV-infected mice 7 and 14 days post vaccination (d.p.v.) with functionalized $\mathrm{CaP}$ nanoparticles. Representative dot plots of the analysis are shown. b Ratios of fully activated CD4 ${ }^{+} \mathrm{CD} 43^{+}$or $\mathrm{CD} 8^{+} \mathrm{CD} 43^{+}$effector T cells (EFF) to Foxp3 ${ }^{+} \mathrm{CD}^{+}$T cells. c Frequencies of $\mathrm{Ki} 7^{+} \mathrm{Foxp}^{+} \mathrm{CD}^{+}$regulatory T cells. $\mathbf{d}$ Correlation of the percentage of GzmB expressing tetramer stained FV-specific CD8 ${ }^{+} \mathrm{T}$ cells to frequencies of Foxp3 ${ }^{+} \mathrm{CD}^{+}{ }^{+}$T cells 14 d.p.v. with PBS (left) or functionalized CaP NPs (right). Combined results of three independent experiments are shown. Bars represent mean \pm SEM. Statistical analysis was performed by student's $t$ test. ${ }^{*} p<0.05$; ${ }^{* *} p<0.01$; ${ }^{* * *} p<0.001$ 


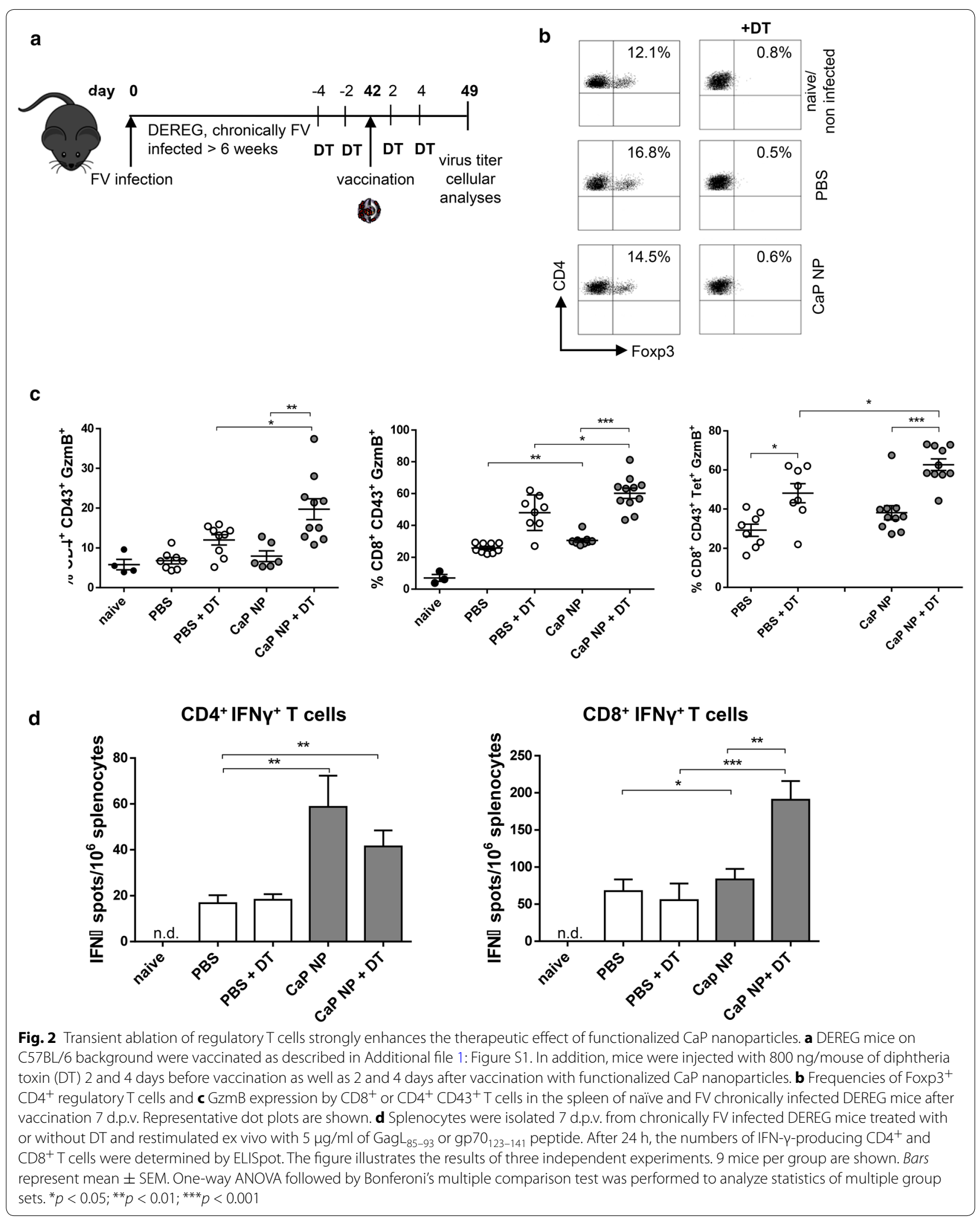




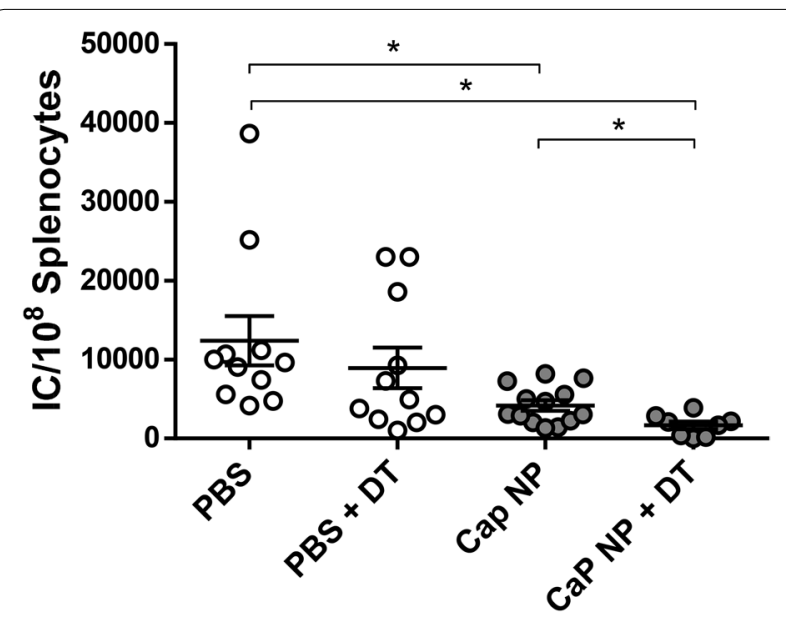

Fig. 3 Combinational therapy of regulatory $\top$ cell depletion and vaccination with functionalized CaP nanoparticles strongly enhances retroviral clearance. Chronically FV-infected DEREG mice were vaccinated as described in Fig. 2.7 d.p.v., mice were sacrificed, and infectious centers in the spleen were determined. Results of four independent experiments were combined. Bars represent mean \pm SEM. One-way ANOVA followed by Bonferoni's multiple comparison test was performed to analyze statistics of multiple group sets. ${ }^{*} p<0.05$

far, it has not been tested if the combination of anti-viral vaccination with the blockade of CCR4 has a potentiating effect on the immune response. Therefore, we vaccinated chronically FV infected mice with functionalized $\mathrm{CaP}$ nanoparticles or with a combination of $\mathrm{CaP}$ nanoparticles and an antagonist for CCR4, respectively. 7 days after vaccination $\mathrm{T}$ cell responses and viral loads were determined. Pretreatment of mice with a CCR 4 antagonist $4 \mathrm{~h}$ before nanoparticle vaccination did not modulate the frequencies of regulatory $\mathrm{T}$ cells in the spleen compared to nanoparticle vaccination alone nor did the combinational treatment enhance the CTL response (Fig. 4a). In consequence, no differences in the viral loads were detectable between vaccination with nanoparticles and the combinational protocol (Fig. 4a). In addition, a prolonged inhibition of regulatory $\mathrm{T}$ cell migration by treatment of mice $4 \mathrm{~h}$ before and on day 1-4 after the vaccination did also not enhance anti-viral immunity (Fig. 4b). Consequently, treatment of mice with a CCR4 antagonist to inhibit the migration of regulatory $\mathrm{T}$ cells to the side of action does not represent an alternative approach for anti-retroviral therapy.

\section{Discussion}

Viruses such as HBV or HIV possess the ability to evade from the immune system by several mechanisms, like viral evolution or exhaustion of effector $\mathrm{T}$ cells which can lead to persistent infection. The currently available treatments for many of these chronic infections do not lead to satisfactory results. For example antiretroviral therapy (ART) is able to suppress HIV replication, the most prominent member of the retrovirus family, but the fact that HIV persists in reservoirs prevents HIV cure by ART. Therefore, there is a strong need to develop new strategies for therapeutic vaccination against chronic infection. Nanomaterials are discussed as part of potential immune-based therapeutic treatment to reactivate the host's immune response [12, 30]. In our latest report, we demonstrated that the application of $\mathrm{CpG}$ and viral peptide functionalized $\mathrm{CaP}$ nanoparticles leads to significant reactivation of $\mathrm{T}$ cell responses and improves virus control in murine chronic FV infection [17]. We also noticed that Tregs have a strong impact on virus-specific immune responses during chronic retrovirus infection [5]. They seem to have a significant effect on the cytotoxicity of $\mathrm{CD}^{+} \mathrm{T}$ cells during acute chronic FV infection by inhibiting the production of cytotoxic molecules such as granzyme A and B [25]. Thus, the aim of the current study was to determine whether the combinational therapy of nanoparticle-based vaccination with depletion of Tregs could strongly enhance the cytotoxic T cell (CTL) response and opens new options in the fight against chronic retroviral infection.

Our current study demonstrates that a combination of depletion of immunosuppressive Tregs and therapeutic immunization with functionalized $\mathrm{CaP}$ nanoparticles of chronically retrovirus infected mice significantly reduced viral loads by efficiently reactivating the cytotoxic potential of virus-specific $\mathrm{CD}^{+}$and $\mathrm{CD}^{+}$effector $\mathrm{T}$ cells compared to therapeutic vaccination alone. It therefore underlines the considerable influence of Tregs on the effector $\mathrm{T}$ cell response during immunotherapy which should be considered for the development of new vaccination strategies.

Tregs are a subset of $\mathrm{CD} 4^{+} \mathrm{T}$ lymphocytes with the ability to down-regulate the immune system [31]. They are the key modulators of the establishment and/or maintenance of viral chronicity and constitute a barrier to efficient vaccination and immunotherapeutic strategies [32]. The implication of regulatory $\mathrm{T}$ cells in chronic viral infection was first described in mice infected with FV $[33,34]$ and was then extended to other persistent viruses, including HIV [35], HBV [36], and HCV [2]. Especially for HIV patients, it was shown that Tregs similarly to the situation in chronic FV infection accumulate in lymphoid tissues and suppress the anti-HIV response $[35,37]$. Thus, it is becoming increasingly clear that controlling this immunosuppressive cell subset would have widespread clinical applications to fight life-threatening viral diseases [38]. In addition, our current study shows evidence that the Treg population also counteracts the 


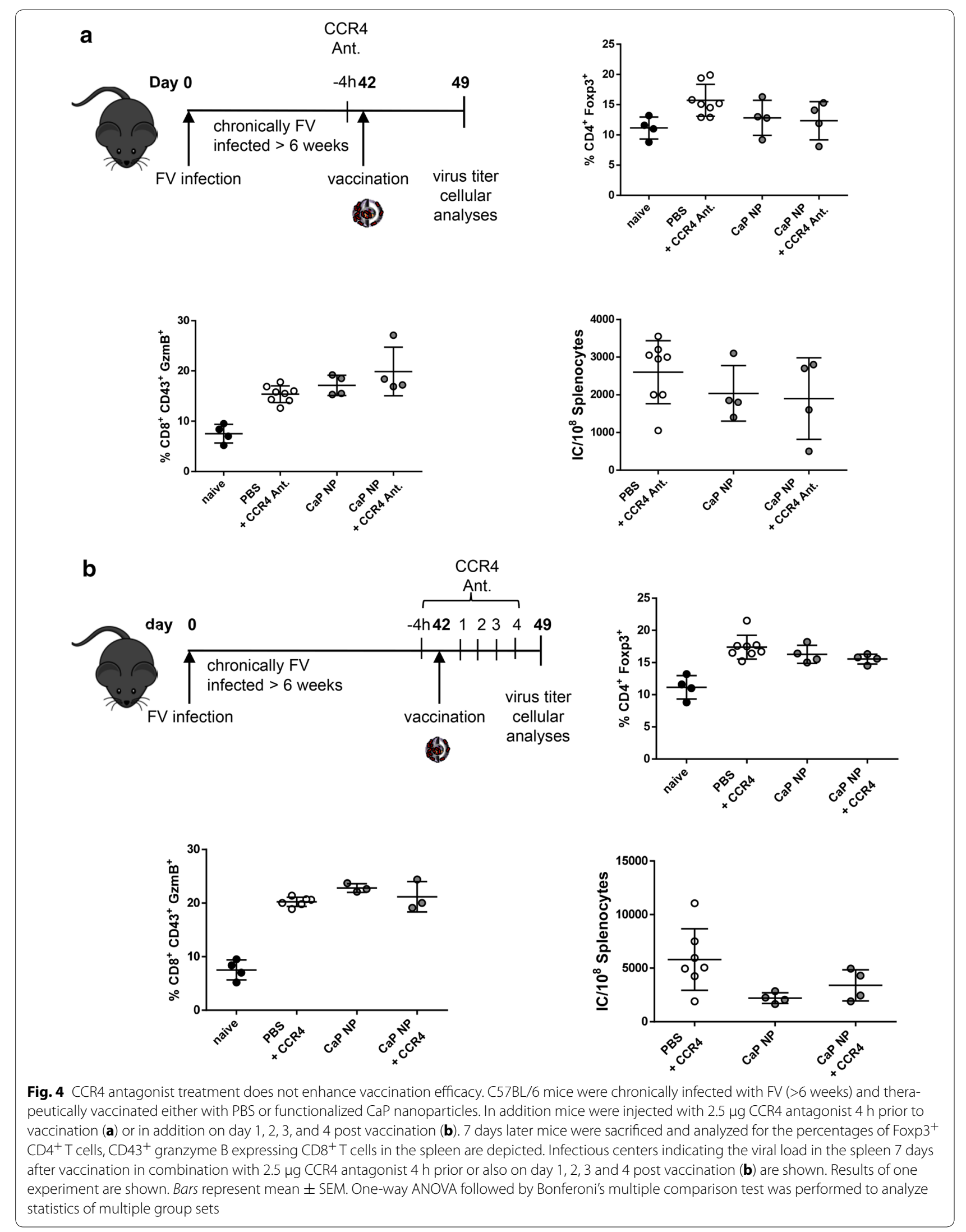


effects of immunotherapeutic vaccination which implies that controlling this subset could further enhance immunotherapy. Suvas et al. [39] have shown that treatment of mice with anti-CD25 antibodies to impair the CD25 ${ }^{\text {high }}$ expressing Treg population resulted in enhanced antigenspecific $\mathrm{CD}^{+} \mathrm{T}$-cell responses accompanied by reduced viral burden in herpes simplex virus-1 infected mice. In addition, we could demonstrate in recent studies that ablation of Tregs from mCMV- and FV-infected mice by using DEREG (DEpletion of Treg) mice was associated with elevated anti-viral $\mathrm{CD} 8^{+} \mathrm{T}$-cell responses showing a restored functionality [5, 40]. Also human studies have highlighted the effects of Tregs in suppressing antiviral effector responses. Macatangay et al. [41] showed that reduced frequencies of virus-specific Tregs during vaccination are important for an efficient therapeutic antiHIV vaccine since this enables the broad activation of effector T cells. Furthermore, an decrease HIV-specific Treg response was associated with an effective DC-vaccine induced immunity in HIV-infected patients [42].

However, the depletion of Tregs should be done with caution since it is known that long term depletion of Tregs can lead to severe autoimmunity syndromes [43]. Temporary Treg depletion or the addition of a Treg blocker along with the vaccine should be considered. Particularly, transient inhibition of Treg migration by using small molecule antagonists to CCR4 was shown to provide robust antigen-specific $\mathrm{CD} 8^{+} \mathrm{T}$ cell responses during anti-tumor vaccination $[28,29]$. However, treatment of chronically FV-infected mice with a CCR4 antagonist before and/or during vaccination with functionalized $\mathrm{CaP}$ nanoparticles within our experimental setting did not improve the vaccination success. Therefore, further studies are needed to elucidate how to manipulate Treg numbers or function during anti-viral vaccination.

Several lines of evidence suggest now that the depletion of Tregs during therapeutic immunization of chronically retrovirus infected mice improves the vaccination efficacy of functionalized $\mathrm{CaP}$ nanoparticles. First, depletion of Tregs during immunization enhanced the relative number of virus-specific IFN- $\gamma$ producing $\mathrm{CD}^{+} \mathrm{T}$ cells. Second, the strongest increase in the frequency of total activated virus-specific cytotoxic $\mathrm{CD}^{+} \mathrm{CD}^{+} 3^{+} \mathrm{GzmB}^{+} \mathrm{T}$ cells was observed after a combined depletion of Tregs and immunization. Since granzyme B has been associated with virus control and killing of virus infected cells in both FV and HIV infection $[44,45]$, induction of cytotoxic T cells is crucial for a therapeutic vaccine. Finally, depletion of Tregs during the therapeutic immunization of chronically FV-infected mice resulted in the lowest viral loads compared to all other treatments tested in this study. Thus Tregs clearly control the CTL response induced by therapeutic vaccination and may reduce its effect.

\section{Conclusion}

Our findings underline that a combination of Treg ablation and therapeutic nanoparticle-based vaccination confers robust antiviral immunity and a sustained control of chronic virus infection.

\section{Methods \\ Mice}

C57BL/6 mice were purchased from Harlan Laboratories (Harlan Winkelmann GmbH, Borchen, Germany). DEREG (DEpletion of REGulatory T cells) mice (expressing eGFP and diphtheria toxin receptor under the control of the forkhead box P3 [Foxp3] promoter) on C57BL/6 background were described previously [26]. All mice used in the experiments were $8-10$ weeks old at time point of infection.

\section{Cells and cell culture}

A murine fibroblast cell line from Mus dunni was maintained in Roswell Park Memorial Institute (RPMI) medium containing $10 \% \mathrm{FCS}$ and $50 \mu \mathrm{g} \mathrm{mL} \mathrm{m}^{-1}$ penicillin/ streptomycin. Cell lines were maintained in a humidified $5 \% \mathrm{CO}_{2}$ atmosphere at $37^{\circ} \mathrm{C}$.

\section{Preparation of functionalized nanoparticles}

$\mathrm{CpG}$ and viral peptide functionalized multi shell $\mathrm{CaP}$ nanoparticles were prepared as described previously [17]. Briefly, nanoparticles were prepared by fast mixing of aqueous solutions of calcium nitrate $(6.25 \mathrm{mM})$ and diammonium hydrogen phosphate (3.74 $\mathrm{mM})$. Immediately after mixing, $1 \mathrm{~mL}$ of the calcium phosphate nanoparticle dispersion was mixed with $0.2 \mathrm{~mL}$ CpG $\left(63 \mu \mathrm{M}=400 \mu \mathrm{g} \mathrm{mL}{ }^{-1}\right)$ and $0.05 \mathrm{~mL}$ of the viral peptides $\mathrm{GagL}_{85-93}$ and $\mathrm{gp} \mathrm{0}_{123-141}\left(1 \mathrm{mg} \mathrm{mL}{ }^{-1}\right)$ were added to form an outer shell of biomolecules Then, calcium nitrate solution $(0.5 \mathrm{~mL})$, diammonium phosphate solution $(0.5 \mathrm{~mL})$ and $\mathrm{CpG}$ solution $(0.2 \mathrm{~mL}, 63 \mu \mathrm{M})$ were subsequently added to form further layers of calcium phosphate and $\mathrm{CpG}$. This led to triple-shell nanoparticles with the composition $\mathrm{CaP} / \mathrm{CpG}+$ peptide/CaP/CpG (from core to shell). The final concentrations of $\mathrm{CpG}$ and GagL/gp70 peptide in the nanoparticle dispersion were $65.3 \mu \mathrm{g} \mathrm{mL} L^{-1}$ (or $10.3 \mu \mathrm{M}$ ) and $20.4 \mu \mathrm{g} \mathrm{mL}^{-1}$, respectively. All inorganic salts were of p.a. (pro analysi) quality. The particles were characterized by scanning electron microscopy (SEM) and dynamic light scattering in the same way as described [17].

\section{TLR-ligand, viral peptides and CCR4 antagonist}

The phosphorothioate-modified class B CpG 1826 was purchased from Eurofins MWG Operon (Ebersberg, Germany). The FV protein derived Gag and gp70 peptide sequences containing MHC I and MHC II-restricted 
epitopes were synthesized with the following sequences: GagL $_{85-93}$, CCLCLTVFL; gp70 ${ }_{123-141}$, EPLTSLTPRCNTAWNRLKL (JPT Peptide Technologies GmbH, Berlin Germany). The CCR4 antagonist CAS 864289-85-0 was purchased from Merck Millipore (Darmstadt, Germany).

\section{Antibodies and flow cytometry}

The monoclonal antibodies $\alpha \mathrm{CD} 4$ (clone RM4-5), $\alpha \mathrm{CD} 8$ (clone 53-6.7) and $\alpha \mathrm{CD} 43$ (clone 1B11) were obtained from BD Biosciences Pharmingen (Heidelberg, Germany). Monoclonal anti-human allophycocyanin (APC)conjugated $\alpha \mathrm{GzmB}$ antibody (clone GB12, Invitrogen, Karlsruhe, Germany) was used for intracellular granzyme B staining. The $\alpha$ Foxp3 antibody (clone FJK-16s) was purchased from ebioscience (Frankfurt, Germany). Intracellular staining with $\alpha$ Foxp3 and $\alpha \mathrm{GzmB}$ was performed as described previously [17]. To detect FV-specific $\mathrm{CD}^{+} \mathrm{T}$ cells a PE-conjugated recombinant MHC-class I H2-D ${ }^{b}$ tetramer (Beckman Coulter) presenting the FV GagL8593 peptide was used. Data was acquired by using an LSR II instrument using DIVA software (BD Biosciences).

\section{Friend virus and chronic infection}

A lactate dehydrogenase-elevating virus (LDV) containing B-cell-tropic, polycythemia-inducing Friend virus-complex (FV) was obtained from BALB/c mouse spleen cell homogenate 14 days post infection. To induce chronic FV infection, naïve FV-resistant C57BL/6 mice were infected with 15,000 spleen focus forming units (SFFU).

\section{Vaccination of mice}

For anti-viral therapeutic vaccination of chronically FV infected and vaccination of naïve mice for in vivo DC activation studies mice were immunized subcutaneously with $100 \mu \mathrm{L}$ PBS or $\mathrm{CaP}$ nanoparticles functionalized with CpG/GagL/gp70 (10.3 $\mu \mathrm{M} \mathrm{CpG}$ and $40.8 \mu \mathrm{g} \mathrm{mL}-1$ GagL/gp70 peptide; $\mathrm{CaP} / \mathrm{CpG} / \mathrm{GagL} / \mathrm{gp} 70 / \mathrm{CaP} / \mathrm{CpG}$ ) in both hind footpads (50 $\mu \mathrm{L}$ each) 6 weeks post FV infection as described before [17].

\section{Depletion of Foxp $3^{+}$regulatory T cells}

To deplete Foxp $3^{+}$regulatory T cells, DEREG mice were injected intraperitoneally with diphtheria toxin (DT) (Merck, Germany) diluted in PBS. $800 \mathrm{ng}$ in total per mouse was injected 4 and 2 days before as well as 2 and 4 days after vaccination with $\mathrm{PBS}$ or functionalized CaP NPs.

\section{IFN- $\gamma$ ELISpot assay}

Interferon- $\gamma$-producing cells were evaluated by ELISpot with a mouse ELISPOTPLUS kit (MABTECH AB, Nacka Strand, Sweden). For evaluation of Interferon- $\gamma$ producing cells after therapeutic vaccination of chronically infected mice, spleen cells or lymph node cells from a cell pool of brachial, axillary, inguinal, and popliteal lymph nodes were restimulated. Restimulation of $2.5 \times 10^{5}$ cells was done with $5 \mu \mathrm{g} \mathrm{mL}^{-1} \mathrm{GagL}_{85-93}$ or gp70 ${ }_{123-141}$ peptide in a 96-well ELISPOT plate for $24 \mathrm{~h}$. IFN- $\gamma$-spots were stained according to the manufacturer's instructions. After the plate was dried, the number of spots was counted by an AID ELISPOT reader using ELISPOT 6.0 software (Mabtech, Nacka Strand, Sweden).

\section{Infectious center assay}

Determination of viral loads by infectious center assay was performed as described previously [46]. Spleens were rinsed with RPMI containing $10 \%$ FCS and $50 \mu \mathrm{g} \mathrm{mL}^{-1}$ penicillin/streptomycin. Spleen cells were counted and serially diluted before seeding them onto Mus dunni cells and incubated under standard tissue culture conditions for 3 days, fixed with ethanol and labeled with the primary F-MuLV Env-specific MAb 720. After washing, a secondary horseradish peroxidase (HRP)-conjugated rabbit antimouse Ig antibody (Dako, Hambrug, Germany) was added. Foci representing infectious centers were detectable after adding of aminoethylcarbazole (SigmaAldrich, Deisenhofen, Germany) as substrate for HRP. Foci were counted and infectious centers (IC)/spleen values were calculated.

\section{Statistical analysis}

Statistical analysis was performed by using student's $t$ test or One-way ANOVA to compare multiple groups using Bonferroni's multiple comparison test. Data analysis was performed using Prism 6.0 software (GraphPad, La Jolla, CA). Statistical significance was set at the level of $p<0.05$.

\section{Ethics statement}

Animal experiments were performed in strict accordance with institutional, state, and federal guidelines. The protocol was approved by the North Rhine-Westphalia State Agency for Nature, Environment and Consumer Protection (LANUF) (Permit Number: G1433/14). All efforts were made to minimize suffering.

\section{Additional file}

\footnotetext{
Additional file 1: Figure S1. A) Schematic illustration of functionalized multi shell calcium phosphate (CaP) nanoparticles. B) C57BL/6 mice were chronically infected with FV ( $>6$ weeks) and therapeutically vaccinated either with PBS or functionalized CaP nanoparticles. 7 or 14 days post vaccination (d.p.v.), mice were sacrificed for analyzes. C) The percentage of $\mathrm{CD}^{+}{ }^{+} \mathrm{CD} 43^{+}$and $\mathrm{CD} 8^{+} \mathrm{CD}_{4}{ }^{+}$effector cells is shown. D) Frequency of granzyme B (GzmB) expressing $\mathrm{CD}_{4} 3^{+} \mathrm{CD} 8^{+} \mathrm{T}$ cells and $\mathrm{CD} 43^{+} \mathrm{CD} 8^{+}$ FV-specific T cells identified by tetramer staining recognizing the $\mathrm{H}-2 \mathrm{D}^{\mathrm{b}}$ restricted FV gag epitope is depicted. E) 7 and 14 d.p.v., mice were sacrificed, and infectious centers in the spleen were determined. The figure summarizes the results of 3 independent experiments. Statistical analysis was performed by student's $t$-test. ${ }^{*} p<0.05 ;{ }^{* *} p<0.005$.
} 


\section{Authors' contributions}

TK designed the experiments, performed the experiments, analyzed the data, did the statistical analysis and wrote the paper. OR, WB, VS and WH carried out experiments. ME, JB and UD designed experiments. TS provide DEREG mice and designed experiments. AMW conceived the experiments and wrote the paper. All authors read and approved the final manuscript.

\section{Author details}

${ }^{1}$ Institute of Medical Microbiology, University Hospital Essen, University of Duisburg-Essen, 45122 Essen, Germany. ${ }^{2}$ Institute of Inorganic Chemistry and Center for Nanointegration (CeNIDE), University of Duisburg-Essen, 45141 Essen, Germany. ${ }^{3}$ Institute of Virology, University Hospital Essen, University of Duisburg-Essen, 45122 Essen, Germany. ${ }^{4}$ Institute of Infection Immunology, TWINCORE, Centre for Experimental and Clinical Medicine, 30625 Hannover, Germany.

\section{Acknowledgements}

We thank Patrick Juszczak, Mechthild Hemmler-Roloff and Svenja Groten for excellent technical assistance. This work was supported by the Deutsche Forschungsgemeinschaft (SFB/Transregio 60 and GRK1949).

\section{Competing interests}

The authors declare that they have no competing interests.

Received: 16 February 2016 Accepted: 28 March 2016 Published online: 14 April 2016

\section{References}

1. Hess C, Altfeld M, Thomas SY, et al. HIV-1 specific CD8+ T cells with an effector phenotype and control of viral replication. Lancet. 2004;363(9412):863-6.

2. Boettler T, Spangenberg HC, Neumann-Haefelin C, et al. T cells with a CD4+ CD25+ regulatory phenotype suppress in vitro proliferation of virus-specific CD8+ T cells during chronic hepatitis C virus infection. J Virol. 2005;79(12):7860-7.

3. Seigel B, Bengsch B, Lohmann V, Bartenschlager R, Blum HE, Thimme R. Factors that determine the antiviral efficacy of HCV-specific CD8(+) T cells ex vivo. Gastroenterology. 2013;144(2):426-36.

4. Belkaid $Y$, Rouse BT. Natural regulatory $T$ cells in infectious disease. Nat Immunol. 2005;6(4):353-60.

5. Dietze KK, Zelinskyy G, Gibbert K, et al. Transient depletion of regulatory $T$ cells in transgenic mice reactivates virus-specific CD8+ T cells and reduces chronic retroviral set points. Proc Natl Acad Sci USA. 2011;108(6):2420-5

6. Zelinskyy G, Dietze K, Sparwasser T, Dittmer U. Regulatory T cells suppress antiviral immune responses and increase viral loads during acute infection with a lymphotropic retrovirus. PLoS Pathog. 2009;5(8):e1000406.

7. Wherry EJ, Blattman JN, Ahmed R. Low CD8 T-cell proliferative potential and high viral load limit the effectiveness of therapeutic vaccination. J Virol. 2005;79(14):8960-8.

8. Dietze KK, Zelinskyy G, Liu J, Kretzmer F, Schimmer S, Dittmer U. Combining regulatory $T$ cell depletion and inhibitory receptor blockade improves reactivation of exhausted virus-specific CD8+ $T$ cells and efficiently reduces chronic retroviral loads. PLoS Pathog. 2013:9(12):e1003798

9. Zelinskyy G, Dietze KK, Husecken YP, et al. The regulatory T-cell response during acute retroviral infection is locally defined and controls the magnitude and duration of the virus-specific cytotoxic T-cell response. Blood 2009:114(15):3199-207.

10. Garcia F, Climent N, Guardo AC, et al. A dendritic cell-based vaccine elicits T cell responses associated with control of HIV-1 replication. Sci Transl Med. 2013;5(166):166ra2.

11. Levy $Y$, Thiebaut $R$, Montes M, et al. Dendritic cell-based therapeutic vaccine elicits polyfunctional HIV-specific T-cell immunity associated with control of viral load. Eur J Immunol. 2014;44(9):2802-10.

12. Liu H, Moynihan KD, Zheng Y, et al. Structure-based programming of lymph-node targeting in molecular vaccines. Nature. 2014;507(7493):519-22.
13. Sahdev P, Ochyl LJ, Moon JJ. Biomaterials for nanoparticle vaccine delivery systems. Pharm Res. 2014;31(10):2563-82.

14. Sokolova V, Knuschke T, Kovtun A, Buer J, Epple M, Westendorf AM. The use of calcium phosphate nanoparticles encapsulating Toll-like receptor ligands and the antigen hemagglutinin to induce dendritic cell maturation and T cell activation. Biomaterials. 2010;31(21):5627-33.

15. Sokolova V, Kozlova D, Knuschke T, Buer J, Westendorf AM, Epple M. Mechanism of the uptake of cationic and anionic calcium phosphate nanoparticles by cells. Acta Biomater. 2013;9(7):7527-35.

16. Knuschke T, Sokolova $\vee$, Rotan $\mathrm{O}$, et al. Immunization with biodegradable nanoparticles efficiently induces cellular immunity and protects against influenza virus infection. J Immunol. 2013;190(12):6221-9.

17. Knuschke T, Bayer W, Rotan $\mathrm{O}$, et al. Prophylactic and therapeutic vaccination with a nanoparticle-based peptide vaccine induces efficient protective immunity during acute and chronic retroviral infection. Nanomedicine. 2014;10(8):1787-98.

18. Hasenkrug KJ, Dittmer U. Immune control and prevention of chronic Friend retrovirus infection. Front Biosci. 2007:12:1544-51.

19. Joedicke JJ, Myers L, Carmody AB, et al. Activated CD8 + T cells induce expansion of Vbeta5+ regulatory T cells via TNFR2 signaling. J Immunol. 2014;193(6):2952-60.

20. Chevalier MF, Weiss L. The split personality of regulatory T cells in HIV infection. Blood. 2013;121(1):29-37.

21. Bayer W, Tenbusch M, Lietz $R$, et al. Vaccination with an adenoviral vector that encodes and displays a retroviral antigen induces improved neutralizing antibody and CD4+ T-cell responses and confers enhanced protection. J Virol. 2010;84(4):1967-76.

22. Dittmer U, Brooks DM, Hasenkrug KJ. Requirement for multiple lymphocyte subsets in protection by a live attenuated vaccine against retroviral infection. Nat Med. 1999:5(2):189-93.

23. Ohs I, Windmann S, Wildner O, Dittmer U, Bayer W. Interleukin-encoding adenoviral vectors as genetic adjuvant for vaccination against retroviral infection. PLoS One 2013:8(12):e82528.

24. Ruan KS, Lilly F. Approach to a retrovirus vaccine: immunization of mice against Friend virus disease with a replication-defective Friend murine leukemia virus. Proc Natl Acad Sci USA. 1992;89(24):12202-6.

25. Zelinskyy G, Werner T, Dittmer U. Natural regulatory T cells inhibit production of cytotoxic molecules in CD8(+) T cells during low-level Friend retrovirus infection. Retrovirology. 2013;10:109.

26. Lahl K, Loddenkemper C, Drouin C, et al. Selective depletion of Foxp3+ regulatory T cells induces a scurfy-like disease. J Exp Med. 2007;204(1):57-63.

27. de Vries IJ, Castelli C, Huygens C, et al. Frequency of circulating Tregs with demethylated FOXP3 intron 1 in melanoma patients receiving tumor vaccines and potentially Treg-depleting agents. Clin Cancer Res. 2011;17(4):841-8.

28. Bayry J, Tartour E, Tough DF. Targeting CCR4 as an emerging strategy for cancer therapy and vaccines. Trends Pharmacol Sci. 2014;35(4):163-5.

29. Bayry J, Tchilian EZ, Davies MN, et al. In silico identified CCR4 antagonists target regulatory $T$ cells and exert adjuvant activity in vaccination. Proc Natl Acad Sci USA. 2008;105(29):10221-6

30. Barouch DH, Deeks SG. Immunologic strategies for HIV-1 remission and eradication. Science. 2014;345(6193):169-74.

31. Wan YY. Regulatory T cells: immune suppression and beyond. Cell Mol Immunol. 2010;7(3):204-10.

32. Zou W. Regulatory T cells, tumour immunity and immunotherapy. Nat Rev Immunol. 2006;6(4):295-307.

33. Iwashiro M, Peterson K, Messer RJ, Stromnes IM, Hasenkrug KJ. CD4(+) T cells and gamma interferon in the long-term control of persistent friend retrovirus infection. J Virol. 2001;75(1):52-60.

34. Zelinskyy G, Kraft AR, Schimmer S, Arndt T, Dittmer U. Kinetics of CD8+ effector T cell responses and induced CD4+ regulatory $T$ cell responses during Friend retrovirus infection. Eur J Immunol. 2006;36(10):2658-70.

35. Nilsson J, Boasso A, Velilla PA, et al. HIV-1-driven regulatory T-cell accumulation in lymphoid tissues is associated with disease progression in HIV/ AIDS. Blood. 2006;108(12):3808-17.

36. Nan XP, Zhang Y, Yu HT, et al. Circulating CD4+ CD25 high regulatory $T$ cells and expression of PD-1 and BTLA on CD4+ T cells in patients with chronic hepatitis B virus infection. Viral Immunol. 2010;23(1):63-70.

37. Betts MR, Nason MC, West SM, et al. HIV nonprogressors preferentially maintain highly functional HIV-specific CD8+T cells. Blood. 2006:107(12):4781-9. 
38. Maizels RM, Smith KA. Regulatory T cells in infection. Adv Immunol. 2011;112:73-136.

39. Suvas S, Kumaraguru U, Pack CD, Lee S, Rouse BT. CD4+CD25+T cells regulate virus-specific primary and memory $C D 8+T$ cell responses. J Exp Med. 2003;198(6):889-901.

40. Jost NH, Abel S, Hutzler M, et al. Regulatory T cells and T-cell-derived IL-10 interfere with effective anti-cytomegalovirus immune response. Immuno Cell Biol. 2014;92(10):860-71.

41. Macatangay BJ, Szajnik ME, Whiteside TL, Riddler SA, Rinaldo CR. Regulatory $T$ cell suppression of Gag-specific CD8 T cell polyfunctional response after therapeutic vaccination of HIV-1-infected patients on ART. PLoS One. 2010;5(3):e9852.
42. Seddiki N, Brezar V, Draenert R. Cell exhaustion in HIV-1 infection: role of suppressor cells. Curr Opin HIV AIDS. 2014;9(5):452-8

43. Vignali DA, Collison LW, Workman CJ. How regulatory T cells work. Nat Rev Immunol. 2008:8(7):523-32.

44. Migueles SA, Osborne CM, Royce C, et al. Lytic granule loading of CD8+ T cells is required for HIV-infected cell elimination associated with immune control. Immunity. 2008;29(6):1009-21.

45. Zelinskyy G, Balkow S, Schimmer S, Werner T, Simon MM, Dittmer U. The level of friend retrovirus replication determines the cytolytic pathway of CD8+ T-cell-mediated pathogen control. J Virol. 2007:81(21):11881-90.

46. Dittmer $U$, Hunsmann G. Antiviral CD4 cell response in simian immunodeficiency virus-infected macaques. J Infect Dis. 1998;177(6):1771-2.

\section{Submit your next manuscript to BioMed Central} and we will help you at every step:

- We accept pre-submission inquiries

- Our selector tool helps you to find the most relevant journal

- We provide round the clock customer support

- Convenient online submission

- Thorough peer review

- Inclusion in PubMed and all major indexing services

- Maximum visibility for your research

Submit your manuscript at www.biomedcentral.com/submit
(O) Biomed Central 